\title{
CHARACTERIZATION OF THREE-DIMENSIONAL DENDRITIC STRUCTURES IN NICKEL-BASE SINGLE CRYSTALS FOR INVESTIGATION OF DEFECT FORMATION
}

\author{
J. Madison $^{1}$, J.E. Spowart ${ }^{2}$, D.J. Rowenhorst ${ }^{3}$, J.Fiedler ${ }^{1}$, T.M. Pollock ${ }^{1}$ \\ ${ }^{1}$ University of Michigan; 2300 Hayward Street; Ann Arbor, MI 48109-2136, USA \\ ${ }^{2}$ Air Force Research Laboratory/RXLM; 2230 Tenth Street; Wright-Patterson AFB, OH 45433-7817, USA \\ ${ }^{3}$ Naval Research Laboratory; 4555 Overlook Avenue S.W; Washington, DC 20375
}

Keywords: Dendritic, Solidification, Mushy Zone, Serial-Section, Reconstruction

\begin{abstract}
During solidification, solute-induced convective instabilities at the solid - liquid interface can result in the formation of defects such as freckles and misoriented grains in superalloy single crystals. These defects can be particularly detrimental to the properties of single crystal nickel-base superalloys. Unfortunately, detailed understanding of fluid flow at the scale of the dendritic structure has yet to be fully understood, particularly under conditions in which heat extraction is non-axial. The objective of this research is to develop a technique for quantifying the dendritic structure and morphology at the solid - liquid interface for the purpose of providing direct input into computational fluid flow modeling. Using the RoboMET.3D serial sectioning system, threedimensional datasets of dendritic structure at the solidification front have been obtained for René N4 abruptly decanted during solidification. Distribution and arrangement of solid and liquid in the vicinity of dendrite tips is analyzed and the implications for defect formation are discussed.
\end{abstract}

\section{Introduction}

Preventing the formation of freckles and/or misoriented grains is important to the manufacturing and performance of single crystal superalloy components. These defects are the result of soluteinduced convective instabilities that occur at the solid-liquid interface during directional solidification [1-4]. The two most common defects observed are isolated, individual high-angle misoriented grains and freckle-chains. Although a number of factors have been identified as contributors to the formation of these defects, including; cooling rates, refractory alloy content and casting size and geometry [3-7], convective flow during solidification is regarded as the precursor event [8-12]. As a result, the most widely used criteria for the prediction of these defects generally consider the ratio of the buoyant to frictional forces, an interaction chiefly quantified by the Rayleigh number $[10,13-17]$. Such a prediction requires not only knowledge of the fluid-flow conditions in the melt but also a detailed understanding of the geometrical domain in which the melt flows. Unfortunately, a definitive understanding of fluid flow at the scale of directionally solidified dendritic structures is still lacking. This is partly due to the many factors governing flow at this level that are both dynamic and difficult to quantify. These factors, captured in the Rayleigh parameter $R_{a}$, Eq. (1), include composition, segregation behavior, permeability, and flow channel geometry:

$$
R_{a}=\frac{\left(\Delta \rho / \rho_{0}\right) g \bar{K} L}{\alpha \nu}
$$

where $\Delta \rho / \rho_{0}$ is the density gradient in the liquid, $g$ is acceleration due to gravity, $K$ is permeability, $L$ is the height of the mushy zone or relative length scale and $\alpha v$ is the product of thermal diffusivity and kinematic viscosity [15]. Alloy chemistry influences the Rayleigh number by means of its inherent effect on the density gradient, diffusivity and viscosity. Permeability however, is dependent upon the dendritic environment through which fluid flow occurs. This research focuses on the development of three-dimensional reconstruction and characterization techniques for dendritic structures that can be used to more accurately quantify the fluid flow environment and consequently provide a more precise approximation of permeability within the dendritic array.

\section{Experimental Procedures}

Using an ALD Vacuum Technologies, Inc. Furnace (see Fig. 1), 4 $\mathrm{kg}$ ingots were directionally solidified in conventional Bridgman mode at the University of Michigan. The alloy used in this study is the commercial superalloy René N4 with a nominal composition of $4.2 \mathrm{Al}-0.05 \mathrm{C}-7.5 \mathrm{Co}-9.8 \mathrm{Cr}-0.15 \mathrm{Hf}-1.5 \mathrm{Mo}-0.5 \mathrm{Nb}-$ 4.8Ta-3.5Ti-6.0W-Ni (wt\%) and solidus and liquidus temperatures of $1300^{\circ} \mathrm{C}$ and $1345^{\circ} \mathrm{C}$ respectively. A withdrawal rate of $2.5 \mathrm{~mm} / \mathrm{min}$ and thermal gradient of $40^{\circ} \mathrm{C} / \mathrm{cm}$ was used. During withdrawal, the investment mold was fractured to evacuate molten liquid from the solidified dendritic structure while leaving the solid structure at the solidification front undisturbed.

Following solidification, a cast elongated plate with a crosssectional area normal to the growth direction of $11.5 \times 3 \mathrm{~cm}$ was produced and samples of approximately $1 \mathrm{~cm} \times 1 \mathrm{~cm} \times 1 \mathrm{~cm}$ were removed from the solid-liquid interface of the casting with slow speed milling saws while exercising care to leave the dendritic front undisturbed. Samples were then vacuum impregnated with Buehler EpoHeat epoxy. Next, using the prototype RoboMET.3D serial sectioning system at Wright-Patterson Air Force Base, (see Fig. 2) mechanical polishing, cleaning and imaging at intervals of $2.2 \mu \mathrm{m}$ through the sample thickness permitted acquisition of a 3$\mathrm{D}$ dataset. Images were taken parallel to the primary growth direction consisting of an 8-image montage. Each image was taken at $10 \mathrm{X}$ with a standard resolution of $0.52 \mu \mathrm{m} /$ pixel. Full details of the RoboMET.3D system have been previously discussed in the literature [18-20].

After a comprehensive data set was obtained, image segmentation was performed using ITT Visual Information Solutions' Interactive Data Language (IDL) along with Adobe Photoshop to render each slice a cleaned, binary image properly aligned for stacking. Using IDL, datasets were converted to three- 
dimensional arrays, for visualization and evaluation of the dendritic structure at the solidification front.

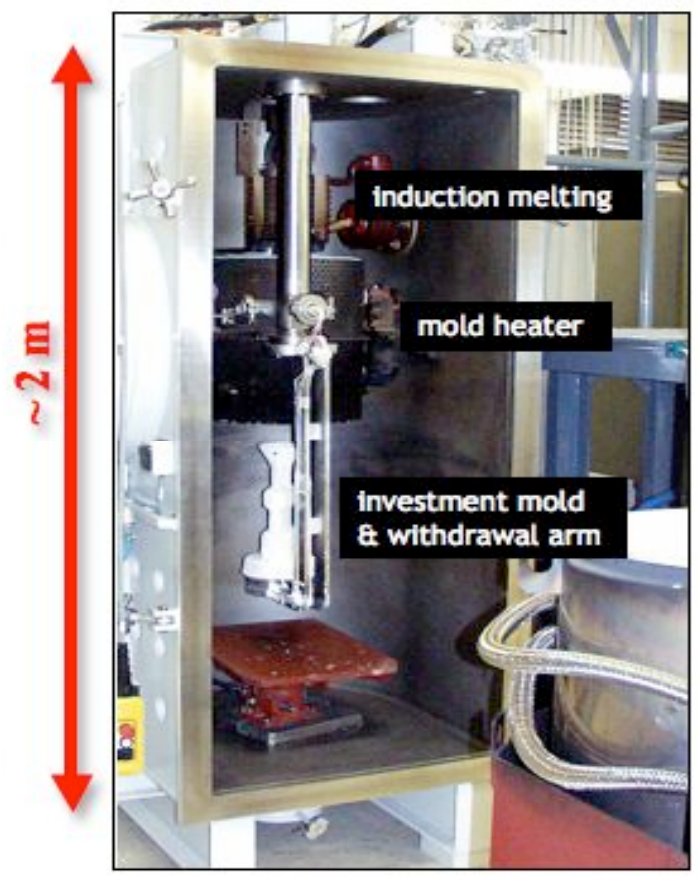

Figure 1: ALD Vacuum Technologies, Inc. Bridgman directional solidification furnace with liquid metal cooling (LMC) capability.

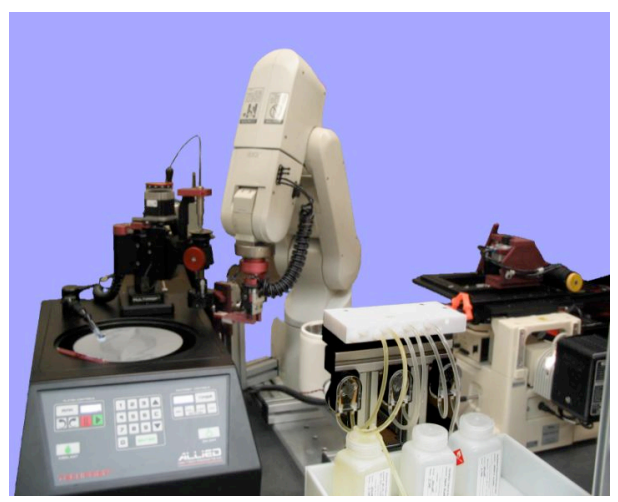

Figure 2: RoboMET.3D automated serial sectioning system with ALLIED metallographic polisher, robotic arm, ultrasonic cleaner and Axiovert Zeiss Inverter Microscope.

Lastly, the three-dimensional arrays were cropped for regions of liquid connectivity and surface meshes were generated using MIMICS software by Materialise followed by volume meshes that were created in GAMBIT by ANSYS. After satisfactory meshing of the interdendritic liquid was accomplished, global smoothing of the structures was introduced to diminish the pronounced tertiary dendritic features and limit flow interaction to the primary and secondary dendrite arms to ensure convergence. FLUENT was used to simulate fluid flow through the dendritic structure in the following manner. A direction of flow is assumed and a pressure gradient is imposed on the structure. Boundary conditions of zero pressure at the outlet and a flow velocity of $100 \mu \mathrm{m} / \mathrm{sec}$ at the inlet with 'no-slip' at the walls was assumed, and interdendritic fluid flow was assumed as steady state. Using Darcy's Law, Eq. (2), permeability in these structures can be calculated as a result of the pressure change. $Q$ is volumetric flow rate, $K$ represents permeability whereas $A$ accounts for cross-sectional area and $L$ is the length over which fluid travels between the pressure difference. Values for viscosity $(\mu)$ and density $(\rho)$ of the molten fluid during simulation have been approximated from calculations and predictions in the literature [21,22].

$$
Q=K A \frac{\Delta P}{\mu L}
$$

\section{Results}

$\underline{\text { Reconstruction }}$

The reconstruction is composed of 727 individual slices comprising a total of $12.6 \mathrm{~GB}$ of image information in its raw form. The removal rate for serial sectioning is shown in Figure 3, where the nominal sectioning thickness is shown as $2.2 \mu \mathrm{m}$ per slice.

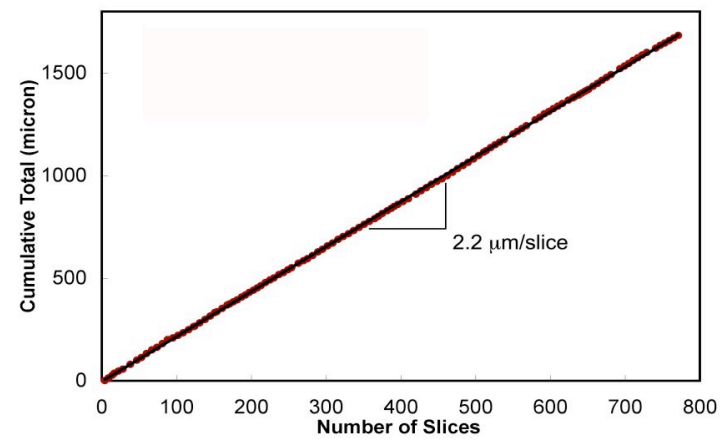

Figure 3: Serial-Sectioning Recession Rate with RoboMET.3D showing material removal as a function of slice quantity for the René N4 sample.

The total reconstructed volume is $2300 \times 2300 \times 1600 \mu \mathrm{m}$ and is shown in Figure 4. Figures 5 and 6 are transverse and longitudinal slices through the dataset respectively, revealing the dendritic patterns present. Approximations of dendrite arm spacing were performed with the digital volume using two separate methods. For primary dendrite arm spacing (PDAS), binary images of individual planes perpendicular to the growth direction of the structure were isolated and primary dendrite cores were counted yielding PDAS measurements according to the following relation:

$$
\lambda_{1}=n_{p}^{-1 / 2}
$$

where $n_{p}$ represents the number of primary cores counted per cross-sectional area [23]. Using this method on a series of sections taken from this reconstruction, as shown in Fig. 5, an average PDAS of $480 \mu \mathrm{m}$ was estimated. Similarly, with regard to secondary dendrite arm spacing (SDAS) thin binary planes of the reconstruction parallel to the primary growth direction, as shown in Fig. 6, were isolated and an average SDAS measurement of $86 \mu \mathrm{m}$ was returned. 


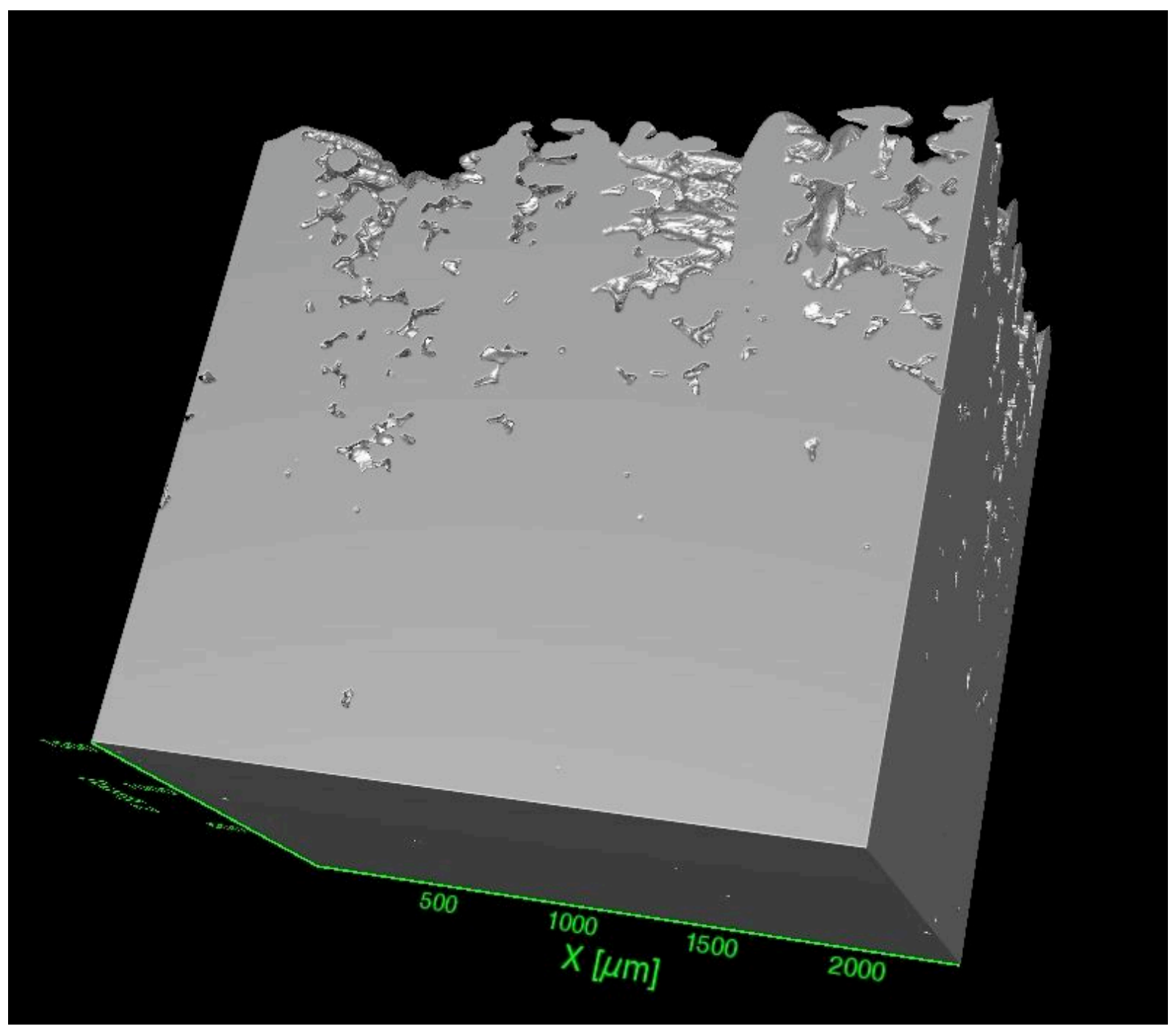

Figure 4 - Reconstructed dendritic solid-liquid interface of René N4, gray represents solidified superalloy, the voids represent interdendritic voids occupied by liquid prior to decanting.

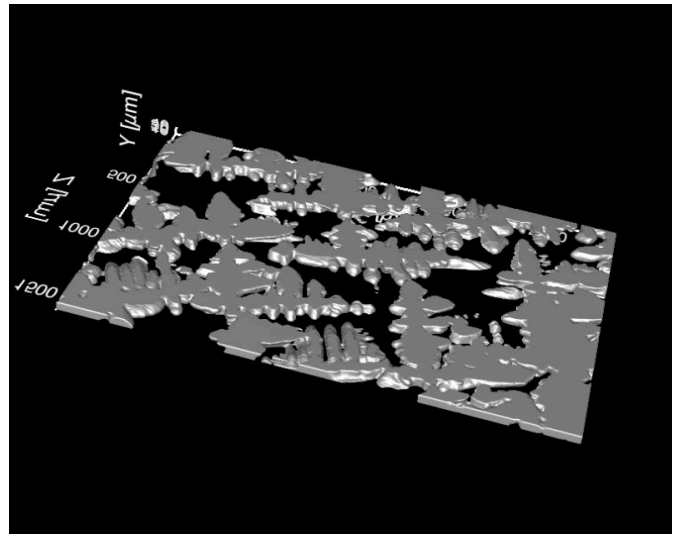

Figure 5 - Transverse cross-section of dendritic structures in which slice orientation shown is perpendicular to the primary growth direction

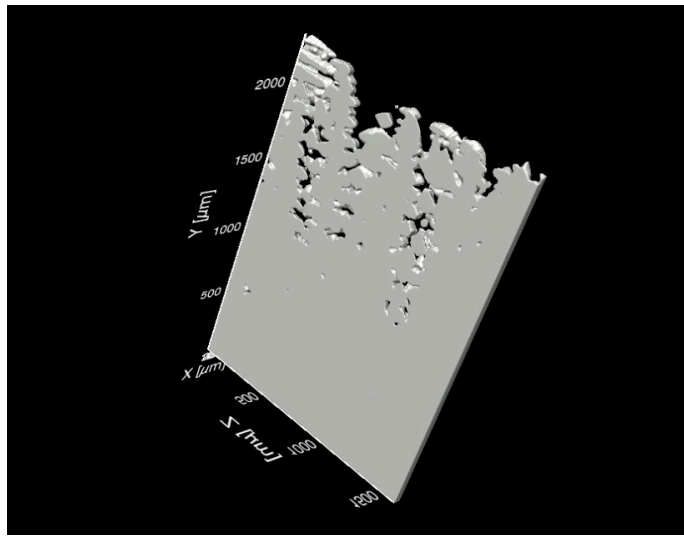

Figure 6 - Longitudinal cross-section of dendritic structures in which slice orientation shown is parallel to the primary growth direction 


\section{Fraction Solid}

By visualizing the structure as a collection of binary images, each pixel location represents either solid material or a void region formerly occupied by liquid. In this way, by summing the pixel quantities representing the presence and absence of material within successive planes along its height, the volume fraction solid $\left(f_{s}\right)$ as a function of height can be measured, Figure 7. Initial inspection reveals an initially moderate decrease in solid fraction followed by a rather precipitous drop in solid fraction wherein approximately eighty percent of the volume solid decreases to zero in the upper $500 \mu \mathrm{m}$ of the mushy zone. This indicates a curved liquidus surface where the fraction of solid as a function of temperature varies non-linearly. There are also smaller volume fluctuations between fractions solid of $0.5 \leq f_{s} \leq 0.9$. These however, are due to locally fluctuating solid fraction caused by the presence of secondary dendrite arms.

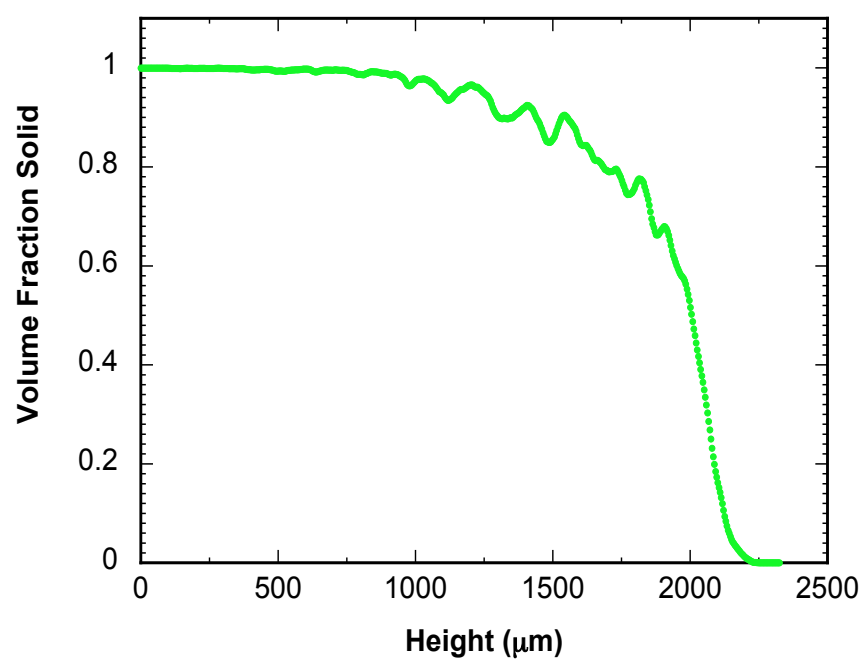

Figure 7: Volume fraction solid as a function of height in René N4 reconstructed mushy zone.

\section{Interdendritic Channel Connectivity}

For convective instabilities to develop, fluid flow through the dendritic structure must occur, making the connectivity of interdendritic channels therefore important. The channels produced by the collection of interdendritic voids throughout the mushy zone possess a high degree of connectivity, yet these channels do not unify all voids. By distinguishing each independent body of interdendritic void in the reconstruction, over 800 individual regions were identified. Importantly, $97.9 \%$ of the total voided regions are composed of a single interconnected channel. Table I summarizes the number of voids and the sum of their physical sizes for a given voxel ("volume-pixel") range. It is interesting to note that the cumulative void percentage obtained by excluding the largest eighteen independent bodies is $0.63 \%$. The largest eighteen bodies detail the location in which molten liquid is the single or overwhelming dominant phase. The collection of remaining bodies detail encased voiding which is consistent with the level of isolated porosity, typically encountered in single crystal materials.
Three-Dimensional Calculation of Cross Flow

For convective instabilities to develop in a dendritic structure, flow across the dendritic array normal to the solidification direction must feed the plumes that flow parallel to the solidification direction and ultimately result in freckles. Thus the influence of dendritic structure on this "cross-flow" normal to the solidification direction is of interest. A cross-sectional volume nominally $200 \times 1000 \times 1500 \mu \mathrm{m}$ was selected due to its location at the dendrite tips as well its high connectivity of interdendritic regions. Surface and volume meshes of interdendritic liquid generated are shown below in Figures 8 and 9 respectively.

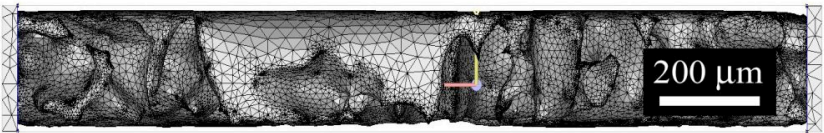

(a)

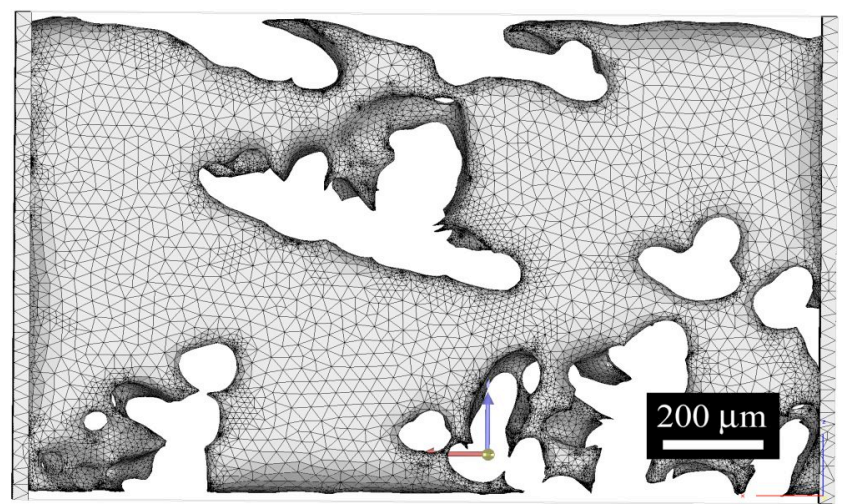

(b)

Figure 8: (a) Side view, parallel to the solidification direction and (b) Top view, normal to the solidification direction of liquid surface mesh generated with MIMICS

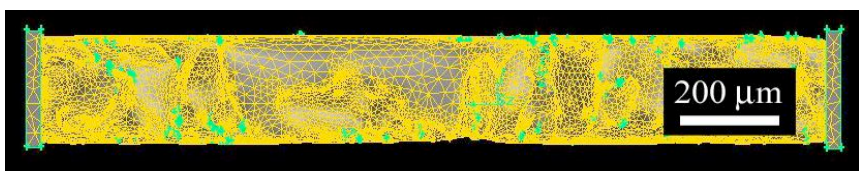

(a)

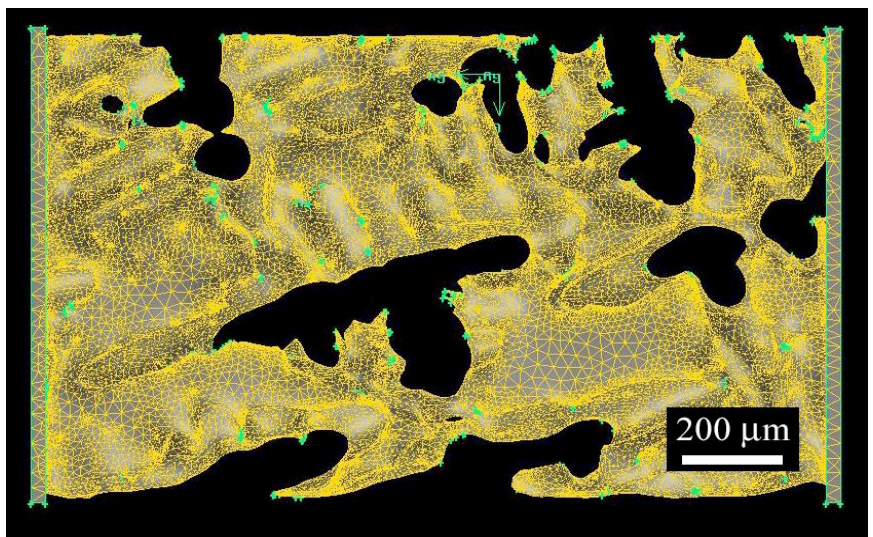

(b)

Figure 9: (a) Side view, parallel to the solidification direction and (b) Bottom view, normal to the solidification direction of liquid volume mesh generated with GAMBIT 


\begin{tabular}{|c|c|c|c|c|c|}
\hline Volume Threshold $\left(\mu \mathrm{m}^{3}\right)$ & Voxel Threshold & No. of Independent Bodies & Cumulative Volume & $\begin{array}{c}\text { Percentage Void } \\
\text { Fraction } \\
\end{array}$ & $\begin{array}{c}\text { Contribution to Total } \\
\text { Voided Regions }\end{array}$ \\
\hline 380700000 & $10^{7}$ & 1 & 1605996489 & $97.9 \%$ & $97.91 \%$ \\
\hline 38070000 & $10^{6}$ & 0 & 0 & $0.00 \%$ & $97.91 \%$ \\
\hline 3807000 & $10^{5}$ & 1 & 4960443 & $0.30 \%$ & $98.21 \%$ \\
\hline 380700 & $10^{4}$ & 16 & 18838565 & $1.15 \%$ & $99.36 \%$ \\
\hline 38070 & $10^{3}$ & 68 & 8238469 & $0.50 \%$ & $99.86 \%$ \\
\hline 3807 & $10^{2}$ & 139 & 1809311 & $0.11 \%$ & $99.97 \%$ \\
\hline 380.7 & $10^{1}$ & 273 & 338958 & $0.02 \%$ & $99.99 \%$ \\
\hline 38.07 & 1 & 337 & 50027 & $0.00 \%$ & $99.99 \%$ \\
\hline
\end{tabular}

*single voxel volume is $38.07 \mu^{3}$

Streamlines illustrating the flow directions in this volumetric cross-section are shown, Figure 10. Here, flow is depicted from left to right and the view presented is the orientation of the microstructure as shown in Figure $8 \mathrm{~b}$. In these simulations, flow is assumed as steady state and grayscale illustrates flow velocities throughout the mushy zone. It can be observed that flow velocity increases in narrow channels where flow is constricted and the flow rate must increase. Flow also seems to be dominated by the primary and secondary dendrite arms found in the central portions of the region. The pertinent range of velocity magnitudes observed range from $175 \mu \mathrm{m} / \mathrm{s}$ to $3500 \mu \mathrm{m} / \mathrm{s}$. These values appear reasonable given the imposed inlet velocity of $100 \mu \mathrm{m} / \mathrm{s}$.

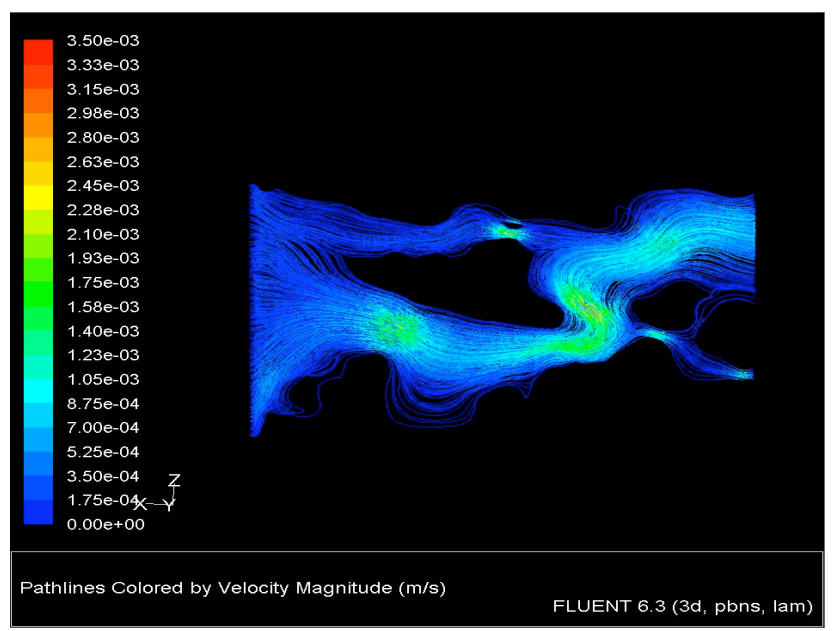

Figure 10: Streamlines of cross flow through a volumetric crosssection of the mushy zone. Solidification direction is normal to the view. Velocity magnitudes are presented in $\mathrm{m} / \mathrm{s}$.

Additionally, pressure contours throughout the structure are shown in Figure 11. Higher pressures are concentrated on the left at the velocity inlet while low pressures are present at the pressure outlet on the right. Pressure gradients are most pronounced in regions of restricted cross-section and high velocity flow. With the imposed flow and disregarding any localized fluxes at the boundary plates, a pressure differential of $14.5 \mathrm{~Pa}$ was measured across the structure. By measuring the local cross-section at the inlet a specific cross-sectional area and volumetric flow rate were returned. These values were then used in a formulation of Darcy's Law, Eq. (2), to derive a solution for permeability. Using this method, permeability calculated for cross-flow in this volume is $1.16 \times 10^{-10} \mathrm{~m}^{2}$

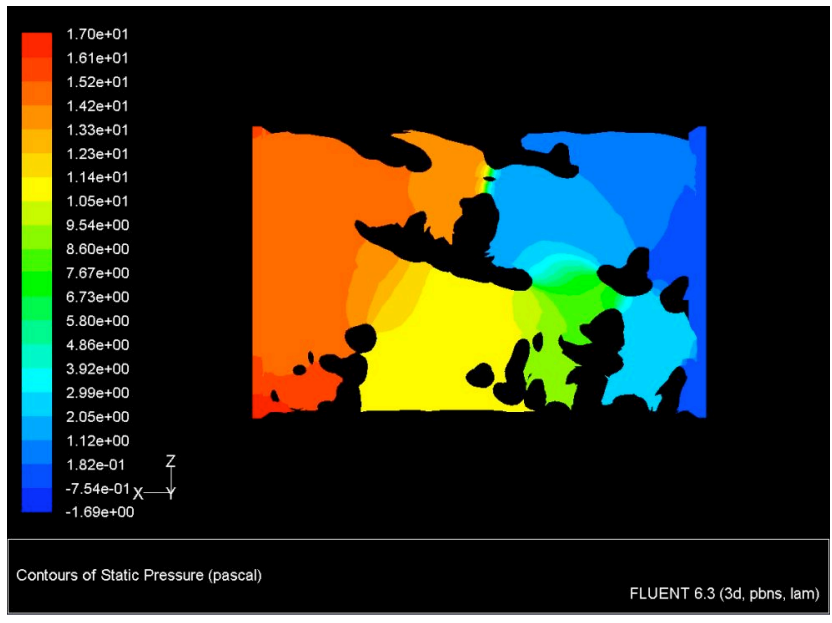

Figure 11: Pressure contours across the reconstructed liquid as a result of cross-flow. An inlet pressure of $17 \mathrm{~Pa}$ is present at the inlet.

\section{Discussion}

Primary and Secondary Dendrites

Dendrite arm spacing has often been used to not only quantify the solidification phenomena but also as an indication of casting quality in directionally solidified structures. The predominant measures are the primary and secondary dendrite arm spacings (PDAS and SDAS respectively) [24-32]. It has been well documented that fundamental relationships exist between dendrite arm spacing and casting parameters of growth rate (V) and thermal gradient $(G)$. As such, with knowledge of $G$ and $V$, an expected morphology and dendritic spacing can be approximated. While variations in the general form of the relationship exist [33, 34], Hunt proposed the following widely accepted relationship for primary dendrite arm spacing $\left(\lambda_{1}\right)$ as a function of $\mathrm{G}$ and $\mathrm{V}$ [35].

$$
\lambda_{1} \propto G^{-1 / 2} * V^{-1 / 4}
$$

While PDAS can be influenced largely by the solidification front curvature and degree of lateral heat extraction, SDAS has been shown to vary fairly consistently with local solidification time according to the following behavior $[36,37]$ : 


$$
\lambda_{2} \propto(G * V)^{-1 / 3}
$$

Figures 12 and 13 show the dependence of PDAS and SDAS as a function of $\mathrm{G}$ and V, Eqs. (4) and (5), measured by Elliott et al. [5] using molds instrumented with thermocouples for verification of experimental thermal gradient. The data were generated using a set of similar withdrawal rate experiments performed in the University of Michigan's Bridgman furnace with and without liquid-Sn assisted cooling [38]. The largest deviations from Eq. (4) occur when there is large-scale transverse dendritic growth. The extent of transverse dendritic growth in the present experiments was extremely limited.

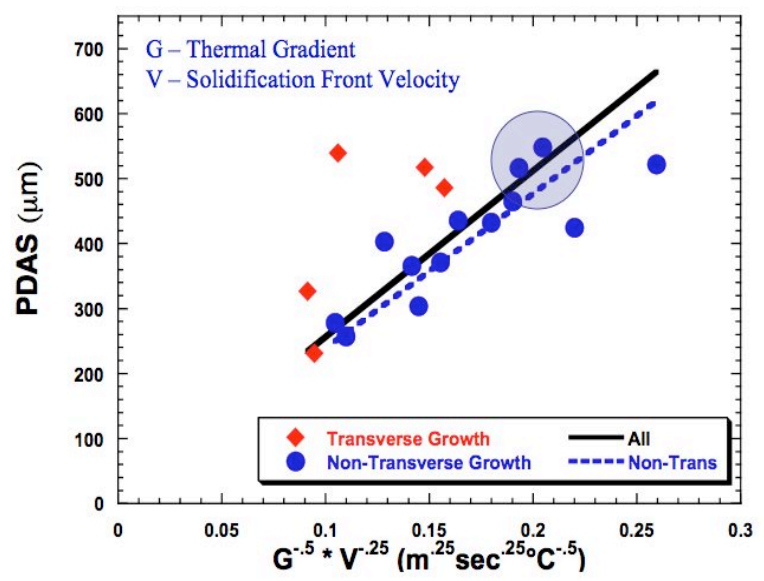

Figure 12: Measured Primary Dendrite Arm spacing plotted as a function of the product of $\mathrm{G}^{-5} * \mathrm{~V}^{-.25}$

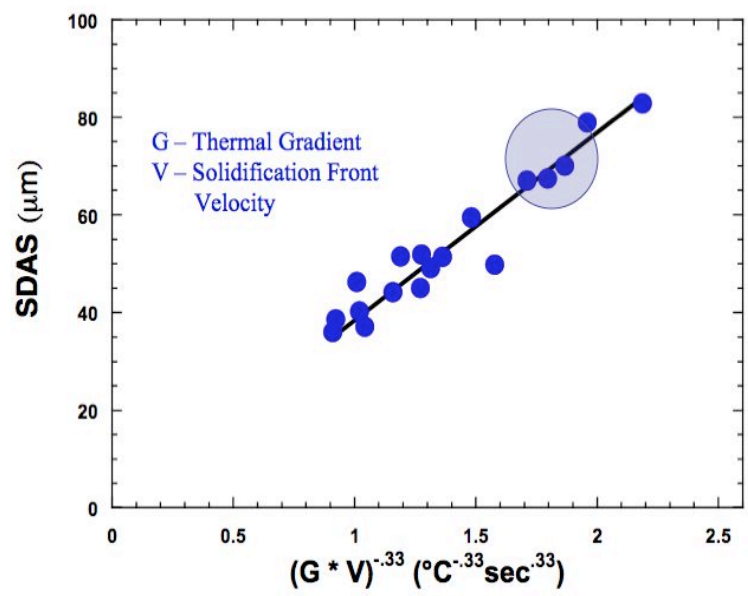

Figure 13: Measured Secondary Dendrite Arm spacing plotted as a function of the product of $\left(\mathrm{G}^{*} \mathrm{~V}\right)^{-.33}$

Using the results in Figs. 12 and 13, local 3-D and further global 2-D PDAS and SDAS measurements were evaluated for comparison. Based on the relationships shown in Eqs. (4) and (5) and taking into account the thermal gradient $(\mathrm{G})$, and solidification front velocity $(\mathrm{V})$, used to produce this casting of René N4, we would expect PDAS in the range of $450-600 \mu \mathrm{m}$ and an SDAS in the range of $60-80 \mu \mathrm{m}$ as highlighted in Figs 12 and 13. Using 2-D metallography on material taken near the vicinity of the reconstruction, the average PDAS was measured as $560 \mu \mathrm{m}$ whereas SDAS expressed an average measure of $82 \mu \mathrm{m}$.
Similarly, by using planar sections of the reconstruction, with a smaller overall cross-section compared to the 2-D measurements, the PDAS was approximated as $480 \mu \mathrm{m}$ and SDAS was approximated at $86 \mu \mathrm{m}$, which is near the range expected. Table II summarizes these results.

Table II. Comparison of Arm Spacing Measures by Technique

\begin{tabular}{|l|c|c|}
\hline & PDAS & SDAS \\
\hline G \& V Calculation & $450-600$ & $60-80$ \\
\hline 2-D Measurement & 560 & 82 \\
\hline 3-D Measurement & 480 & 86 \\
\hline
\end{tabular}

While the 2-D measures compare well with the 3-D measures, the 3-D approximations for PDAS appear to slightly underestimate the 2-D measures due to a smaller cross-section sampled. Using 2-D measures, 1,460 dendrite cores were counted for PDAS whereas for SDAS, a portion of these cores were sectioned and 31 independent measures were taken. Given the limitation of the reconstruction, 255 dendrite cores were counted from within planes of the reconstruction to get the 3-D PDAS approximation whereas 6 representative SDAS measurements were taken by sampling through the volume.

\section{Implications of Volume Fraction Gradient and Voiding}

With a constant temperature gradient and uniform withdrawal rate, a resultant linear variation in fraction solid as a function of distance from the dendrite tips into the solid was not observed for René N4. While the literature has suggested steep declines in the volume fraction solid over the length of the mushy zone, [33, 39] here we have developed an experimental technique to directly measure this critical feature of the mushy zone. Taking the measured volume fraction solid as a function of height in the mushy zone, see Figure 7, over the first $1700 \mu \mathrm{m}$ a decrease of approximately $0.01 \%$ fraction solid per $\mu \mathrm{m}$ is apparent while over the final $500 \mu \mathrm{m}$ a decrease of $0.16 \%$ fraction solid per $\mu \mathrm{m}$ exists. These large-scale gradients in fraction solid will strongly influence fluid flow within the mushy zone. Permeability is highly sensitive to volume fraction, and as such, drastic changes in volume would suggest drastic fluctuations in permeability over the same length scale. Unfortunately, most solidification analyses tend to take an average volume fraction over the mush or consider shorter heights throughout the mushy zone to be reasonably free from large-scale volume fluctuations and associated large-scale fluctuations in permeability $[13,15]$. In the $3-D$ dataset presented, over $95 \%$ of the total voids identified are united with the uppermost body, satisfying a necessary condition for convective flow and solidified material transport. However, this arrangement does not necessarily establish a sufficient condition for convective flow as the limiting flow step for such an event has been proposed as cross-flow parallel to the growth direction of the secondary dendrites $[40,41]$. While further investigation of mean path diameter, length and volume of these channels is in progress, initial observation of the largest single body connected to the region of superheated liquid reveals an interesting feature. The mushy zone, as illustrated in Figure 4, extends over a height of roughly $1875 \mu \mathrm{m}$. The height of the largest interconnected body is approximately $900 \mu \mathrm{m}$. This would suggest that the potential for convective flow exists as far as halfway down into the mushy zone. 


\section{Permeability}

The above Navier-Stokes fluid flow simulation suggests we can successfully calculate permeability in these structures based upon the pressure differential. It should be noted that the reconstructed liquid used in the fluid flow model shown in this work does exhibit a high volume fraction liquid $\left(f_{L}\right)$ gradient over its $200 \mu \mathrm{m}$ height (roughly $0.4 \leq f_{L} \leq 0.7$ ). As such, the region of higher volume fraction likely dominates the flow calculations derived here. Nonetheless a degree of agreement exists between similar treatments of cross-flow permeability in the literature. Bhat et. al derived a dimensionless value for permeability in cross-flow through dendritic structures [42] as a function of liquid fraction denoted by $g_{L}$. This was accomplished by dividing permeability by the square of the PDAS. By employing this convention, we arrive at a value for dimensionless permeability in this structure $\mathrm{K}^{\prime}=\mathrm{K} / \lambda_{1}{ }^{2}$ equal to $3.68 \times 10^{-4}$. While this value is near the range of those reported by Bhat and Porier [42, 43], their treatments suggest dimensionless permeability values in the range of $10^{-2}-$ $10^{-3}$ for liquid volume fractions in the range of 0.4 to 0.7 . However, it should also be noted, their treatments report findings primarily in the $\mathrm{Pb}-\mathrm{Sn}$ system with remarkably lower PDAS. The techniques for permeability analysis presented here will now permit future assessments of the influence of dendritic microstructure on fluid flow and defect formation.

\section{Conclusions}

- The primary and secondary dendritic arm spacings of the reconstruction are consistent with two-dimensional measures and are within the range of expected values based upon withdrawal rates and thermal gradients.

- For the commercial alloy René N4, volume fraction solid as a function of height does not vary linearly with the temperature gradient as might be expected. This strongly affects the permeability as a function of depth throughout the mushy zone and particularly in the upper $25 \%$.

- At the solid-liquid solidification front, as observed in the 3-D reconstruction, the connectivity of the uppermost body of interdendritic liquid during solidification contains over ninety percent of the total interdendritic liquid and extends down through nearly half of the entire mushy zone height.

- Permeability within these structures can be calculated based upon the observed pressure differential resulting from fluid flow. The associated permeability values calculated offer reasonable agreement with similar treatments of permeability in the literature.

\section{Acknowledgements}

The authors would like to acknowledge the assistance of T. Van Vranken and L. Graham of PCC Airfoils for their fabrication of molds for this work as well as the unparalleled technical expertise of C. Torbet of the University of Michigan. Useful discussions with G. Spanos of the Naval Research Laboratory, P. Voorhees of Northwestern University as well as K. Thornton of the University of Michigan are also greatly appreciated. Student funding from the ONR HBEC Future Faculty Fellowship as well as project support from the AFOSR MEANS-II Program, Grant No. FA9550-05-1-0104 is also gratefully acknowledged.

\section{References}

1. S. M. Copley, A. F. Giamei, S. M. Johnson, \& M. F. Hornbecker, "The Origin of Freckles in Unidirectionally Solidified Castings," Metall. Trans, 1 (A) (1970), 2193-2204

2. A. F. Giamei \& B. H. Kear, "On the Nature of Freckles in Nickel Base Superalloys," Metall. Trans, 1 (A) (1970), $2185-$ 2192.

3. T. M. Pollock, "The growth and elevated temperature stability of high refractory nickel-base single crystals," Materials Science and Engineering B, B32 (1995), 255-266.

4. T. M. Pollock \& W. H. Murphy, "The Breakdown of SingleCrystal Solidification in High Refractory Nickel-Base Alloys," Metall. Mater. Trans. A, 27A (4) (1996), 1081-1094.

5. A. J. Elliott, S. Tin, W. T. King, S. C. Huang, M. F. X. Gigliotti, \& T. M. Pollock, "Directional Solidification of Large Superalloy Castings with Radiation and Liquid-Metal Cooling: A Comparative Assessment," Metall. Mater. Trans. A, 35A (2004), 3221-3231.

6. F. Scheppe, I. Wagner, \& P. R. Sahm, "Advancement of the Directional Solidification Process of a Ni-Al-W Alloy" (Paper presented at the Mat. Res. Soc. Symp, Boston, MA, 2001), N.5.7.1-6

7. S. Tin, "Carbon Additions and Grain Defect Formation In Directionally Solidified Nickel-Base Superalloys," University of Michigan, Ph.D. Thesis, (2001), 1-155.

8. J. C. Heinrich, S. Felicelli, P. Nandapurkar, \& D. R. Poirier, "Thermosolutal Convection during Dendritic Solidification of Alloys: Part II. Nonlinear Convection," Metall. Trans. B, 20B (1989), 883-891.

9. S. Motakef, "Interference of Buoyancy-Induced Convection with Segregation During Directional Solidification: Scaling Laws," J. Crystal Growth, 102 (1990), 197-213.

10. G. Muller, G. Neumann, \& H. Matz, "A Two-Rayleigh Number Model of Buoyancy-Driven Convection in Vertical Melt Growth Configurations," J. Crystal Growth, 84 (1987), 36-49.

11. S. Tin \& T. M. Pollock, "Stabilization of Thermosolutal Convective Instabilities in Ni-Based Single-Crystal Superalloys: Carbide Precipitation and Rayleigh Numbers," Metall. Mater. Trans. A, 34A (2003), 1953-1967.

12. S. Tin, T. M. Pollock, \& W. Murphy, "Stabilization of Thermosolutal Convective Instabillities in Ni-Based SingleCrystal Superalloys: Carbon Additions and Freckle Formation," Metall. Mater. Trans. A, 32A (2001), 1743-1753.

13. C. Beckermann, J. P. Gu, \& W. J. Boettinger, "Development of a Freckle Predictor via Rayleigh Number Method for SingleCrystal Nickel-Base Superalloy Casting," Metall. Mater. Trans. A, 31A (10) (2000), 2545-2557.

14. D. A. Nield, "The Thermohaline Rayleigh-Jeffreys Problem," J. Fluid Mech, 29 (3) (1967), 545-558. 
15. J. C. Ramirez \& C. Beckermann, "Evaluation of a RayleighNumber-Based Freckle Criterion for Pb-Sn Alloys and Ni-Base Superalloys," Metall. Mater. Trans. A, 34A (7) (2003), 15251536.

16. S. Tin \& T. M. Pollock, "Predicting Freckle Formation in Single Crystal Ni-Base Superalloy," Journal of Materials Science, 39 (2004), 7199-7205.

17. M. G. Worster, "Instabilities of the Liquid and Mushy Regions During Solidification of Alloys," J. Fluid Mech, 237 (1992), 649669.

18. B. Maruyama, J. E. Spowart, D. J. Hooper, H. M. Mullens, A. M. Druma, C. Druma, et al., "A new technique for obtaining three-dimensional structures in pitch-based carbon foams," Scripta Materialia, 54 (2006), 1709-1713.

19. J. E. Spowart, "Automated serial sectioning for 3-D analysis of microstructures," Scripta Materialia, 55 (2006), 5-10.

20. J. E. Spowart, H. M. Mullens, \& B. T. Puchala, "Collecting and Analyzing Microstructures in Three Dimensions: A Fully Automated Approach," Journal of Materials, 55 (10) (2003), 3537.

21. F. J. Cherne III \& P. A. Deymier, "Calculation of Viscosity of Liquid Nickel by Molecular Dynamics Methods," Acta Materialia, 39 (11) (1998), 1613-1616.

22. K. Mukai, Z. Li, \& K. C. Mills, "Prediction of the Densities of Liquid Ni-Based Superalloys," Metall. Mater. Trans. B, 36B (2005), 255-262.

23. D. G. McCartney \& J. D. Hunt, "Measurements of Cell and Primary Dendrite Arm Spacings in Directionally Solidified Aluminum Allloys," Acta Metallurgica, 29 (1981), 1851-1863.

24. A. M. Glenn, S. P. Russo, \& P. J. K. Paterson, "The Effect of Grain Refining on Macrosegregation and Dendrite Arm Spacing of Direct Chill Cast AA5182," Metall. Mater. Trans. A, 34A (2003), 1513-1523.

25. R. N. Grugel \& Y. Zhou, "Primary Dendrite Spacing and the Effect of Off-Axis Heat Flow," Metall. Mater. Trans. A, 20A (1989), 969-973.

26. S. C. Huang \& M. E. Glicksman, "Fundamentals of Dendritic Solidification-II. Development of Sidebranch Structure," Acta Metallurgica, 29 (1981), 717-734.

27. C. M. Klaren, J. D. Verhoeven, \& R. Trivedi, "Primary Dendrite Spacing of Lead Dendrites in Pb-Sn and Pb-Au Alloys," Metall. Mater. Trans. A, 11A (11) (1980), 1853-1861.

28. W. Kurz \& D. J. Fisher, "Dendrite Growth at the Limit of Stability: Tip Radius and Spacing," Acta Metallurgica, 29 (1981), 11-20.

29. L. Makkon, "Primary dendrite spacing in constrained solidification," Materials Science and Engineering A, A148 (1991), 141-143.
30. W. R. Osorio, P. R. Goulart, G. A. Santos, C. Moura Neto, \& A. Garcia, "Effect of Dendrite Arm Spacing on Mechanical Properties and Corrosion Resistance of Al 9 Wt Pct Si and Zn 27 Wt Pct Al Alloys," Metallurgical and Materials Transactions A, 37A (8) (2006), 2525-2538.

31. R. Trivedi, "Interdendritic Spacing: Part II. A Comparison of Theory and Experiment," Metall. Trans. A, 15A (1984), 977-982.

32. M. Vijayakumar \& S. N. Tewari, "Dendrite spacings in directionally solidified superalloy PWA-1480," Materials Science and Engineering A, A132 (1991), 195-201.

33. M. C. Flemings, "Solidification of Castings and Ingots," Solidification Processing, ed. (New York, NY: McGraw-Hill, Inc, 1974), 146-154

34. W. Kurz \& D. J. Fisher, "Solidification Microstructure: Cells and Dendrites," Fundamentals of Solidification, ed. (Enfield, NH: Trans Tech Publications, 1998), 80-87

35. J. D. Hunt, "Cellular and Primary Dendrite Arm Spacings," Solidification and Casting of Metals, ed. J. D. Hunt (London: The Metals Society, 1979), 3-9

36. M. C. Flemings, "Structure Control in Cast Metals," Solidification Technology, ed. J. J. Burke, M. C. Flemings, \& A. E. Gorum (Chestnut Hill, MA: Brook Hill Publishing Company, 1974), 3-14

37. R. Mehrabian, "Segregation Control in Ingot Solidification," Solidification Technology, ed. J. J. Burke, M. C. Flemings, \& A. E. Gorum (Chestnutt Hill, MA: Brook Hill Publishing Company, 1974), 299-315

38. A. J. Elliott, G. B. Karney, M. F. X. Gigliotti, \& T. M. Pollock, "Issues in Processing By the Liquid-Sn Assisted Directional Solidification Technique," Superalloys 2004, ed. K. A. Green, T. M. Pollock, H. Harada, T. E. Howson, R. C. Reed, J. J. Schirra, \& S. Walston (Warrendale, PA: The Minerals, Metals \& Materials Society, 2004), 421-430

39. W. Kurz \& D. J. Fisher, "Solute Redistribution," Fundamentals of Solidification, ed. (Enfield, NH: Trans Tech Publications, 1998), 117-130

40. S. M. Roper, S. H. Davis, \& P. W. Voorhees, "An Analysis of Convection in a Mushy Layer With a Deformable Permeable Interface," J. Fluid Mech, 596 (2008), 333 - 352.

41. S. M. Roper, S. H. Davis, \& P. W. Voorhees, "Convection in a Mushy Zone Forced by Sidewall Heat Lossess," Metall. Mater. Trans. A, 38A (5) (2007), 1069 - 1079.

42. M. S. Bhat, D. R. Poirier, \& J. C. Heinrich, "Permeability for Cross Flow Through Columnar-Dendritic Alloys," Metall. Mater. Trans. B, 26B (1995), 1049-1056.

43. D. R. Poirier, "Permeability for Flow of Interdendritic Liquid in Columnar-Dendritic Alloys," Metallurgical and Materials Transactions B, 18B (1987), 245-255. 